\title{
REANÁLISIS DE ASPECTOS CONTROVERSIALES DE LA FONOLOGÍA DEL CHEDUNGUN HABLADO EN ALTO BIOBÍO: EL ESTATUS FONÉTICO-FONOLÓGICO DE LAS INTERDENTALES [t], [n] y [1]
}

Reanalysis of controversial aspects of chedungun spoken in Alto Biobio phonology: phonetic and phonological status of the interdental consonants [t], [n] y [1]

\author{
Gastón F. Salamanca Gutiérrez* \\ Jaime Patricio Soto-Barba** \\ Juan Héctor Painequeo Paillán*** \\ Manuel Jesús Jiménez Mardones****
}

Resumen

Este artículo tiene como foco de estudio la fonología segmental del mapudungun, en general, y el estatus de los fonos interdentales [t], [n] y [1] en el chedungun hablado en Alto Biobío, en particular. Se elicitó una lista léxica adaptada de Croese (1980), 30 colaboradores adultos, bilingües de chedungun y español, pertenecientes a 10 localidades pehuenches de esta comuna (3 colaboradores de cada una). Mediante evidencia cuantitativa, visual, palatográfica y de contraste en ambiente análogo, se concluye que dichos fonos tienen estatus fonémico en la zona señalada.

Palabras claves: fonemas del mapuche, chedungun, pehuenche, interdentales.

Abstract

This article focuses on the Mapudungún segmental phonology in general, and the status of the interdental phones [t], [n] and [1] from the Chedungun spoken in Alto Biobío in particular. An adapted lexicon list by Croese (1980) was elicited from 30 adult bilingual assistants (Chedungun and Spanish speakers), belonging to 10 towns of this community (three from each one). Through the quantitative, visual, palatographic and analog environment contrast we concluded that those phones have phonemic status in the mentioned area.

Key words: phonemes of the mapuche, pehuenche, interdental consonants, chedungun.

\section{INTRODUCCIÓN}

El estatus de las consonantes interdentales [t], [n] y [1] en el mapudungun hablado en Chile constituye un tema recurrente en la literatura fonético-fonológica acerca de esta lengua originaria de nuestro país. Si solo nos referimos a las descripciones prominentes desde Echeverría (1964) en adelante ${ }^{1}$, se puede apreciar que existe una discrepancia en cuanto a la constatación de la presencia o establecimiento del estatus fonémico de estos

\footnotetext{
${ }^{1}$ Aunque ya el Padre Valdivia (1606) y Fray Félix de Augusta (1916), por ejemplo, reconocían su existencia.
} 
segmentos. En efecto, Echeverría (1964), Salas (1976, 1978), Lagos (1981, 1984), Salamanca (1997), Sadowsky et al. (2013), Pérez (2014), Painequeo (2015), y Sánchez y Salamanca (2015), entre otros, dan cuenta de su existencia en tanto fonos y fonemas; mientras que Croese (1980), Sánchez (1989) y Smeets (1989), entre otros, dan cuenta de su escasa ocurrencia o de la pérdida de su estatus de fonemas. La afirmación de Croese (1980), por ejemplo, es elocuente en este sentido: "Después de una observación cuidadosa [...], a través de casi toda la Araucanía, debemos concluir que las (inter)dentales están prácticamente perdidas" (p. 14).

Ahora bien, respecto de la variedad del mapudungun que nos ocupa, dos han sido también los análisis de estos sonidos: a) considerarlos alófonos de los fonemas alveolares $/ \mathrm{t}, \mathrm{n}, \mathrm{l} / \mathrm{y}$ b) asignarles estatus fonémico separado. Respecto de la primera interpretación, Sánchez (1989) señala: “... [t] [ [n] , [1] (inter)dentales carecen de estatus de fonema..." (p. 293); mientras que Salamanca (1997) afirma que "Los fonos interdentales poseen estatus de fonemas en el pehuenche del Alto Biobío" (p. 119).

Este artículo muestra uno de los resultados del Proyecto Fondecyt 1131095 y presenta evidencias de distinta naturaleza que, a nuestro juicio, respaldan la asignación de estatus fonémico a tales segmentos.

\section{MARCO DE REFERENCIA Y ESTUDIOS FONÉTICO-FONOLÓGICOS ANTERIORES}

Como planteamos en el proyecto de investigación referido (Fondecyt, 1131095), uno de los marcos de referencia centrales escogidos para llevar a cabo el reanálisis de los aspectos controversiales del chedungun, es el descriptivismo taxonómico, cuyos aportes en el ámbito de la fonética y fonología para la descripción de vernáculos tiene como hitos prominentes los trabajos históricos de Pike (1947) y, más recientemente, de Salas (1997), Burquest (2009), y Salamanca, Cifuentes y Figueroa (2011). Este marco de referencia ha tenido una probada pertinencia y productividad para la descripción de vernáculos en nuestro país, como lo prueban, entre otros, los trabajos descriptivos del mapuche realizados por Echeverría (1964), Salas (1976 y 1978), Álvarez-Santullano (1986a 1986b), Lagos (1981, 1984), Salamanca (1997), Henríquez (2004), Salamanca, Aguilar, Alvear y Barrrientos (2009), Salamanca y Quintrileo (2009), Pérez (2014), Sánchez y Salamanca (2015), y Salamanca, Mena y Henríquez (2015).

\section{PREGUNTAS Y OBJETIVOS DE INVESTIGACIÓN}

Este es un estudio descriptivo, cuyas preguntas de investigación que procura responder son: ¿se encuentran vigentes los segmentos interdentales [t] , [n] y [1] en el chedungun hablado en Alto Biobío? y, de ser así, ¿qué estatus fonémico presentan? De este modo, los objetivos planteados son: 1) determinar la vigencia (o no) de los segmentos interdentales [t], [n], y [1] y, de ocurrir estos segmentos, 2) determinar su estatus fonémico. 


\section{CONSIDERACIONES METODOLÓGICAS}

La metodología empleada incluyó, por una parte, los procedimientos clásicos aplicados al trabajo de campo y análisis fonético-fonológico de los vernáculos chilenos, esto es, la discriminación auditiva del material fónico y el análisis distribucional de los segmentos (Pike, 1947; Burquest, 2009); y, por otra, la aplicación de procedimientos que caracterizan la incursión más moderna en el análisis fonético-fonológico de lenguas vernáculas, como son la evidencia visual con apoyo tecnológico (filmación focalizada y análisis palatográfico) y la cuantificación de las realizaciones de los fonemas puestos en foco ${ }^{2}$.

\subsection{CONSIDERACIONES METODOLÓGICAS RESPECTO DEL TRABAJO DE CAMPO}

\subsubsection{RECOLECCIÓN DE DATOS}

La recolección de datos se realizó en 10 localidades de Alto Biobío, lo que implica una cobertura apreciablemente mayor respecto de lo que fue el trabajo de campo realizado por Sánchez (1989) y Salamanca (1997). En efecto, estos investigadores recolectaron sus datos en las comunidades de Cauñicu y Malla Malla, respectivamente; mientras que en nuestro estudio se trabajó en las localidades de Pitril, Cauñicu, Malla-Malla, Trapa-Trapa y Butalelbun (por el sector del valle del Queuco), y El Avellano, Chenqueco, Quiñelon, Chevquelavquen y Guallali-El Barco (por el sector del valle del Biobío). Es importante señalar que incluir un análisis fonético-fonológico con datos provenientes de la zona del curso del río Biobío constituye un aporte relevante en sí mismo, pues, al día de hoy, no hay reportes focalizados en las características fonético-fonológicas del chedungun hablado en este sector. Así, debido a la cobertura que alcanza esta investigación, se puede hablar con propiedad de las características de la fonología del Alto Biobío y no de una comunidad en particular.

\subsubsection{COLABORADORES}

La muestra estuvo constituida por 3 colaboradores por localidad, lo que da 30 hablantes nativos entrevistados. Este aspecto proyecta a nuestra investigación -junto con las de Croese (1980) y Lagos (1981) - entre las de mayor cobertura realizada en territorio "mapuchehablante" en Chile 3 . Dichos colaboradores fueron seleccionados de acuerdo con su competencia en el vernáculo y, desde luego, la ausencia de impedimento físico y mental para la tarea solicitada. Valga relevar aquí la participación del peñi Dr. Héctor Painequeo, quien, en tanto miembro de la etnia mapuche y hablante nativo fluido de mapudungun, utilizó las claves culturales que se precisaban para que, desde el inicio, esta investigación no fuera vista por las comunidades como una intromisión más del mundo winka en el mundo mapuche, sino que se percibiera como un esfuerzo por dar cuenta de

\footnotetext{
${ }^{2}$ Otros tópicos que se abordan en el Proyecto, en general, contemplan también la utilización de espectrografía.

${ }^{3}$ Lagos entrevistó a 27 colaboradores y Croese a 33.
} 
las características de la lengua, que cautela el respeto a las formas tradicionales de acercamiento a la cultura ${ }^{4}$.

\subsubsection{INSTRUMENTOS}

El instrumento que se utilizó en esta investigación fue una lista léxica, que tuvo como base la aplicada por Croese (1980), para postular su división dialectal, aunque incluyó más ítemes que contenían los segmentos problemáticos en las descripciones del mapudungun. Así, la cantidad total de enunciados transcritos para cubrir todos los frentes investigativos propuestos en el Proyecto mencionado fue de 7.688; y respecto de los segmentos puestos en foco en este artículo, la cantidad de tokens analizados fue de 1880.

\subsection{CONSIDERACIONES METODOLÓGICAS RESPECTO DEL ANÁLISIS FONÉTICO- FONOLÓGICO}

Como hemos dicho en apartados precedentes, la metodología de esta investigación contempló un análisis visual y auditivo estándar, un análisis visual con apoyo externo (filmación), un análisis palatográfico y un análisis distribucional. Las transcripciones se realizaron de acuerdo con los símbolos propuestos por el Alfabeto Fonético Internacional (versión actualizada en 2005).

\subsubsection{ANÁLISIS VISUAL Y AUDITIVO ESTÁNDAR}

El análisis visual estándar se basa en la observación directa, en el momento en que el colaborador emite el enunciado; ahí se hacen las anotaciones respectivas. El análisis auditivo estándar, por su parte, incluye una audición pasiva y deliberada del material registrado. Para ello se utiliza una grabadora ad hoc; en nuestro caso, la grabadora utilizada fue una TASCAM DR-100, modelo que ha sido utilizado, en investigaciones anteriores con buenos resultados.

\subsubsection{ANÁLISIS VISUAL CON APOYO EXTERNO}

Cada sesión se filmó con una cámara Handycam Sony DCR-DVD108. Después del trabajo de campo se procedió a analizar detenidamente los registros, con el fin de determinar las características de los segmentos puestos en foco. Sin duda, la posibilidad de analizar las imágenes la cantidad de veces que fuese necesario constituyó una ventaja mayor de este procedimiento.

\footnotetext{
${ }^{4}$ También expresamos nuestra inmensa gratitud al peñi $\mathrm{H}$. Manquepi por tender los puentes necesarios para concretar las sesiones de entrevista y contribuir a que, en la mayoría de los casos, estas se realizaran en un ambiente distendido y cordial.
} 


\subsubsection{PALATOGRAFÍA}

Anderson (2008) señala que "Static palatography is a 'field-friendly' technique that can provide valuable, detailed information about the articulatory characteristics of speech sounds" (p. 26). Respecto de sus características:

Static palatography (also known as direct palatography) uses an edible, paint-like Marking material to record the contact pattern of the tongue with the roof of the mouth during an utterance. It is especially applicable to the field situation because, apart from a video camera, most of the necessary supplies can be found in larger towns. Additional advantages of the method are its portability, its low cost in comparison with electronic systems of gathering articulatory phonetic data, and the information it yields regarding both the tongue and the palate $(2008$, p. 1).

Por ejemplo, en Sadowsky, et al. (2013) se entregan 8 palatogramas como evidencia de la oposición entre la serie (inter)dental y la serie alveolar, en la zona de Huapi.

\subsubsection{ANÁLISIS DISTRIBUCIONAL}

Este es el procedimiento utilizado por la mayoría de las descripciones fonológicas clásicas del mapudungun. Como hemos dicho, este marco de referencia ha tenido una probada pertinencia y productividad para la descripción de vernáculos en nuestro país. Pike (1947) y Burquest (2009) proponen partir de las siguientes premisas para el análisis fonémico: a) los sonidos se ven afectados por los ambientes en que aparecen, b) los sonidos de una lengua presentan tendencia a la simetría y c) series características de sonidos ejercen una presión estructural en la interpretación fonémica de segmentos o series fónicas sospechosas. También coinciden en proponer que dos sonidos articulatoriamente similares pueden estar en una relación de contraste, alternancia o complementariedad y, de acuerdo con ello, pueden ser considerados fonemas diferentes (si contrastan) o dos alófonos de un mismo fonema (si alternan en un mismo contexto, y no hay neutralización, o si se excluyen en las mismas posiciones).

\section{ANÁLISIS Y RESULTADOS}

\subsection{OCURRENCIA DE LOS SEGMENTOS INTERDENTALES [t, n,, 1$]$}

\subsubsection{EVIDENCIA POR MEDIO DEL VISIONADO DE LAS FILMACIONES}

Las siguientes dos series de imágenes muestran la articulación de sonidos interdentales. La primera de ellas captura el momento en que colaboradores del valle del Queuco articulan segmentos interdentales en las palabras ['po.lo] 'mosca', ['an.to] 'sol' y [po.nnon] 'hígado', respectivamente. La segunda serie captura el momento en que colaboradores del valle del Biobío articulan segmentos interdentales en las palabras [la] 'muerto', [va.tfan.to] 'hoy' y [na.'nəy] 'nuera', respectivamente. 
Gastón Salamanca, Jaime Soto-Barba, Juan Héctor Painequeo y Manuel Jesús Jiménez

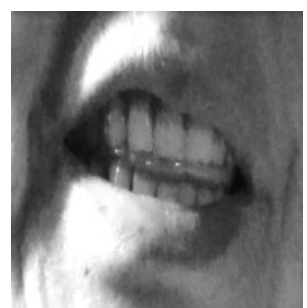

Imagen 1: Realización del fono [1] en un hablante del valle del Queuco

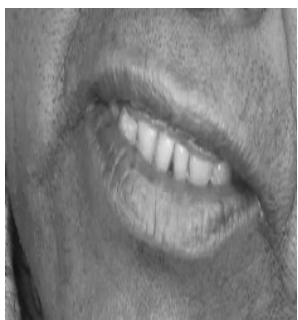

Imagen 2: Realización del fono [t] en un hablante del valle del Queuco

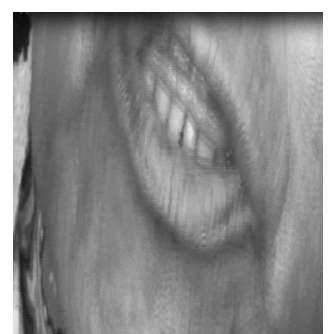

Imagen 3: Realización del fono [n] en un hablante del valle del Queuco

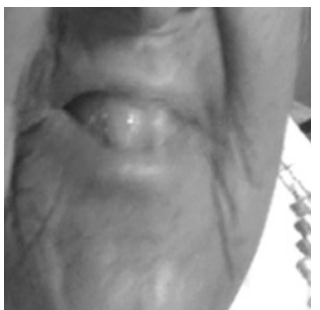

Imagen 4: Realización del fono [1] en un hablante del valle del Biobío 
Reanálisis de aspectos controversiales de la fonología del chedungun hablado

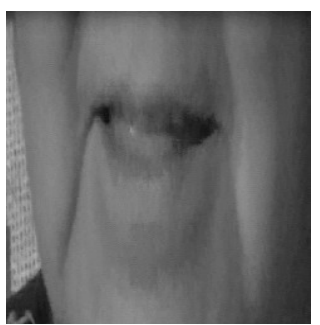

Imagen 5: Realización del fono [t] en un hablante del valle del Biobío

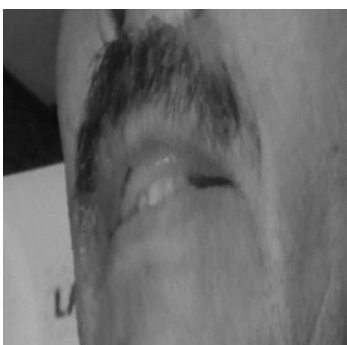

Imagen 6: Realización del fono [n] en un hablante del valle del Biobío

\subsubsection{EVIDENCIA MEDIANTE LA CUANTIFICACIÓN DE LOS SEGMENTOS}

Ahora, si bien es cierto que estos segmentos ocurren, como se observa en las imágenes anteriores, la frecuencia con que se presentan no es idéntica para cada segmento. En efecto, al elicitar palabras cuya expectativa de ocurrencia eran los segmentos interdentales, se obtuvieron los siguientes resultados ${ }^{5}$ :

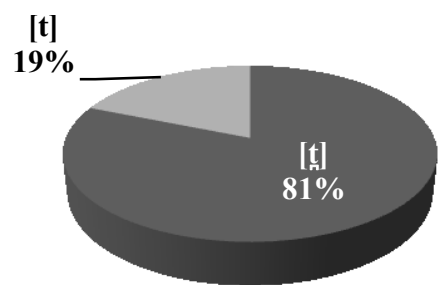

Gráfico 1: Realizaciones interdentales y alveolares de /t/

\footnotetext{
5 Es importante señalar que la palabra "remedio" -reportada con una consonante lateral interdental, en Augusta (1916), Catrileo (1995) y Salas (1992)- presentó un muy bajo porcentaje de realizaciones [1] en nuestros datos $(22,7 \%)$. Es factible aquí la posibilidad de que la forma básica de la entrada léxica en el chedungun del Alto Biobío incluya la consonante lateral alveolar (/la.wen/) y no la consonante lateral interdental.
} 


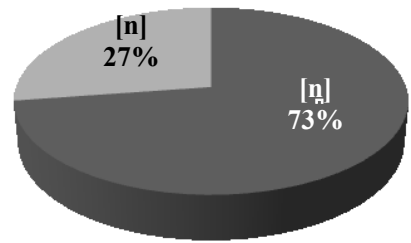

Gráfico 2: Realizaciones interdentales y alveolares de /n/

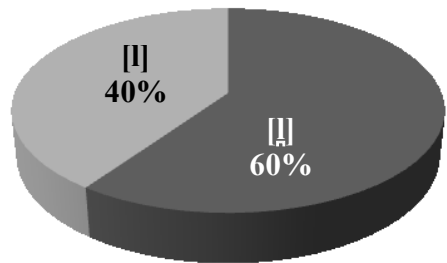

Gráfico 3: Realizaciones interdentales y alveolares de /L/

Es importante destacar que era esperable que el porcentaje de realizaciones interdentales no fuera altísimo, pues de otra manera difícilmente se hubiese constituido en un tema controversial.

\subsection{ESTATUS FONÉMICO DE LOS SEGMENTOS PUESTOS EN FOCO}

\subsubsection{EVIDENCIA POR MEDIO DEL ANÁLISIS DISTRIBUCIONAL}

Presentamos, a continuación, pares submínimos que evidencian el estatus de fonemas distintos de los segmentos que nos ocupan. Respecto de la evidencia proveniente por esta vía, y no necesariamente mediante el par mínimo, Salas (1997, p. 127-128) señala:

[...] el par mínimo (contextos idénticos) es una especialización del par submínimo (contextos análogos), de manera que probada la ocurrencia de los sonidos A y B en situación de analogía de contexto, la posibilidad de ocurrencia de A y B en identidad de contexto (par mínimo) queda garantizadamente incluida. Refutada la ocurrencia de A y B en contextos análogos, la posibilidad misma de existencia de un par mínimo entre A y B queda automáticamente excluida.

Y ejemplifica con el mapudungun:

[...] en mapuche la separación fonémica entre la lateral alveolar [1] y la lateral interdental [1] se apoya suficientemente en la distribución de ambos fonos en un mismo contexto, por ejemplo, ante la vocal [a], como en: laftra 'chico, petiso' y lafken 'mar, lago', distribución que es permisiva de par mínimo. De hecho, hemos atribuido estatus fonémico separado a ambos fonos, /1/ vs. /1/, sin pares mínimos a la vista. Para efectos del análisis solo fue gratificante que una vez 
hecha la descripción apareciera años después, por casualidad, el par mínimo: küla 'tres' vs. küla 'quila'. La distribución fonémica de mapuche /1/ vs. /1/ no existe porque existe ese par mínimo, sino al revés, el par mínimo existe porque $/ 1 / \mathrm{y} / 1 / \mathrm{son}$ fonemas separados.

\subsubsection{PARES SUBMÍNIMOS PARA LA OPOSICIÓN [t] VERSUS $[\mathrm{t}]$}

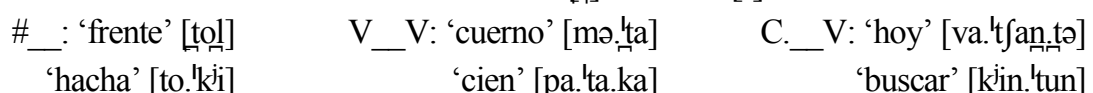

4.2.1.2. PARES SUBMIINIMOS PARA LA OPOSICIÓN [n] VERSUS [n]

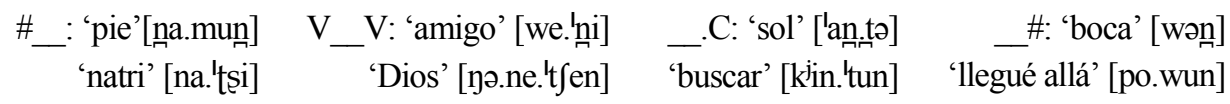

\subsubsection{PARES SUBMÍNIMOS PARA LA OPOSICIÓN [1] VERSUS [1]

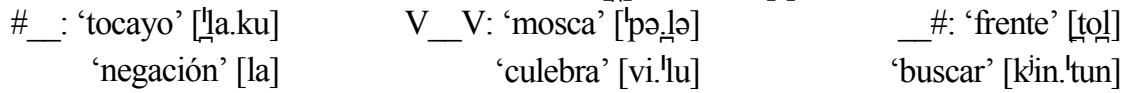

Es esencial destacar que estas oposiciones se producen consistentemente tanto en el valle del Queuco, como del Biobío.

\subsubsection{CONSISTENCIA EN PALABRAS E INFORMANTES}

En sintonía con los resultados anteriores, se manifiesta una consistencia en la producción de las interdentales [t, n, 1$]$ en determinadas palabras y en determinados informantes. En efecto, se puede apreciar, por ejemplo, que palabras como 'marido' [vo.tta] y 'sol' ['an.tə] tienen porcentajes de $94 \%$ y $93 \%$ de realizaciones interdentales [t], respectivamente; en tanto que 'Araucaria' [pe.'wen] y 'nuera' [na.'nəy] se articulan en $84,4 \%$ y $77,2 \%$ de los casos, respectivamente, con la consonante interdental [n] ; por último, las palabras 'cuello' y 'mosca' se articulan en 78,3\% y 90,7\% de los casos, respectivamente, con el segmento [1].

Asimismo, se puede observar que el $61 \%$ de nuestros colaboradores presenta $60 \%$ o más de realizaciones interdentales del fonema $/ 1 / ; 88 \%$, presenta $60 \%$ o más de realizaciones interdentales del fonema $/ \mathrm{n} / ;$ y $94 \%$, presenta $60 \%$ o más de realizaciones interdentales del fonema /t/. En esta misma dirección, conviene destacar también que para cada uno de estos fonemas por lo menos un colaborador realizó $100 \%$ de segmentos interdentales allí donde era expectable su ocurrencia.

\subsubsection{EVIDENCIA PALATOGRÁFICA}

Por último, con la finalidad de hacer aún más visible la ocurrencia de dos puntos de articulación (interdental y alveolar) en el caso de los enunciados 'boca' 
[wən] vs. 'llegué allá' [po.wun], 'cuerno' [mo.ta] vs. 'cien' [pa.ta.ka], y 'mosca' ['pə.lo] vs. 'tres' ['kə.la], se aplicó la técnica de la palatografía a dos de nuestros colaboradores más competentes (uno del valle del Queuco y otro del valle del Biobío). Los resultados se muestran a continuación:

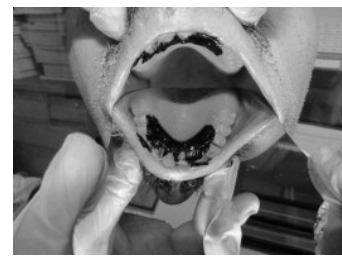

Figura 7: Palatografía para el fono [1]

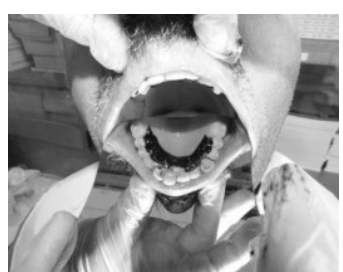

Figura 8: Palatografía para el fono [1]

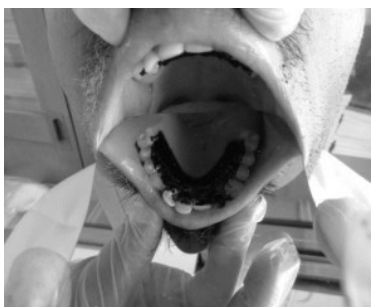

Figura 9: Palatografia para el fono $[\mathrm{n}]$

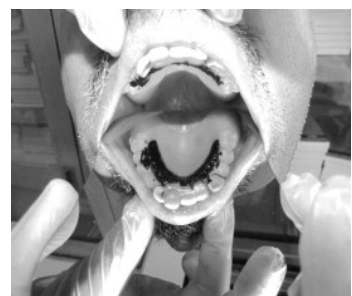

Figura 10: Palatografía para el fono $[\mathrm{n}]$ 


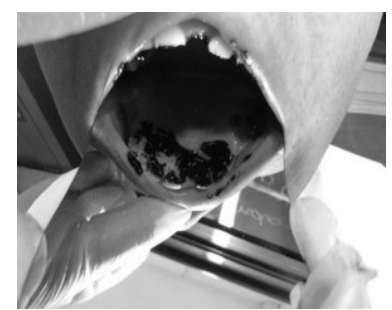

Figura 11: Palatografia para el fono [t]

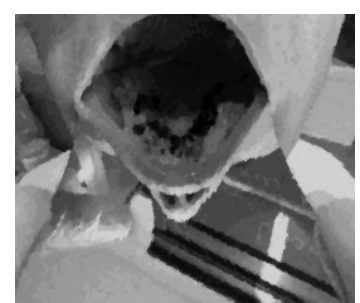

Figura 12: Palatografia para el fono $[\mathrm{t}]$

Nótese cómo en el caso de los segmentos dentales (imágenes 7, 9 y 11) hay una pigmentación oscura más prominente en la cara interior de los dientes, producto del contacto más intenso del ápice de la lengua con esta zona, lo que no se observa -al menos no con la misma intensidad- en el caso de los segmentos alveolares (imágenes $8,10$ y 12$)$.

\subsection{COMPARACIÓN CON OTRAS DOS LOCALIDADES CORDILLERANAS}

El subapartado que sigue incluye una comparación de los resultados obtenidos en nuestro estudio con los que se presentan en Sánchez y Salamanca (2015), y Pérez (2014), los cuales corresponden a dos variantes habladas en las comunas cordilleranas meridionales de Lonquimay y Curarrehue, respectivamente.

\subsubsection{COMPARACIÓN CON EL MAPUDUNGUN HABLADO EN LONQUIMAY}

Los siguientes 2 gráficos muestran los porcentajes de ocurrencia de los segmentos interdentales y alveolares de los fonemas que nos ocupan, en Alto Biobío y Lonquimay. En Alto Biobío estos porcentajes son: para [t] y [t], 81\% y 19\%, respectivamente; para [n] y [n], 73\% y $27 \%$; y para [1] y [1] 60\% y 40\%. En Lonquimay, en tanto, estos porcentajes son: para [t] y [t], 67\% y 33\%; para [n] y [n], 78\% y $22 \%$; y para [1] y [l], 64\% y $36 \%$ en el mismo orden. Nótese que, salvo matices, estas tendencias son similares. 

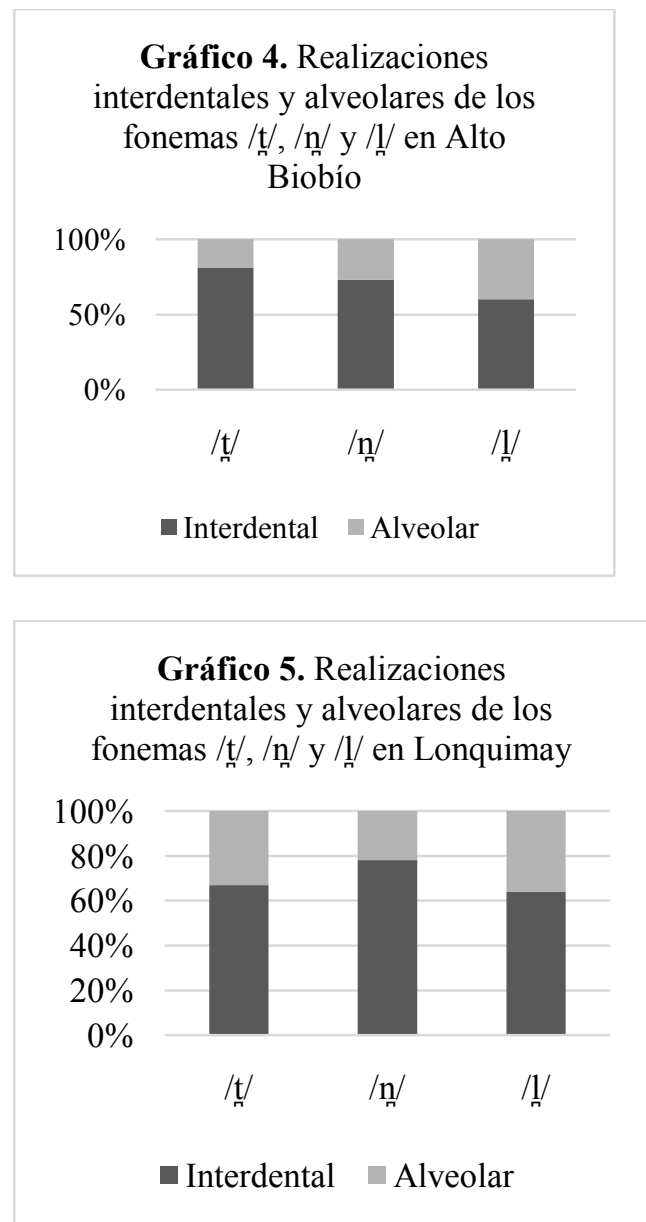

\subsubsection{COMPARACIÓN CON EL MAPUDUNGUN HABLADO EN CURARREHUE}

En Curarrehue, de acuerdo con el reporte de Pérez (2014), los porcentajes de realizaciones son: para [t] y [t], $74 \%$ y $26 \%$, respectivamente; para [n] y [n], $57 \%$ y $43 \%$, respectivamente; y para [1] y [1], 33\% y $67 \%$, respectivamente. Los siguientes gráficos muestran estos porcentajes, en comparación con los obtenidos en Alto Biobío: 
Reanálisis de aspectos controversiales de la fonología del chedungun hablado
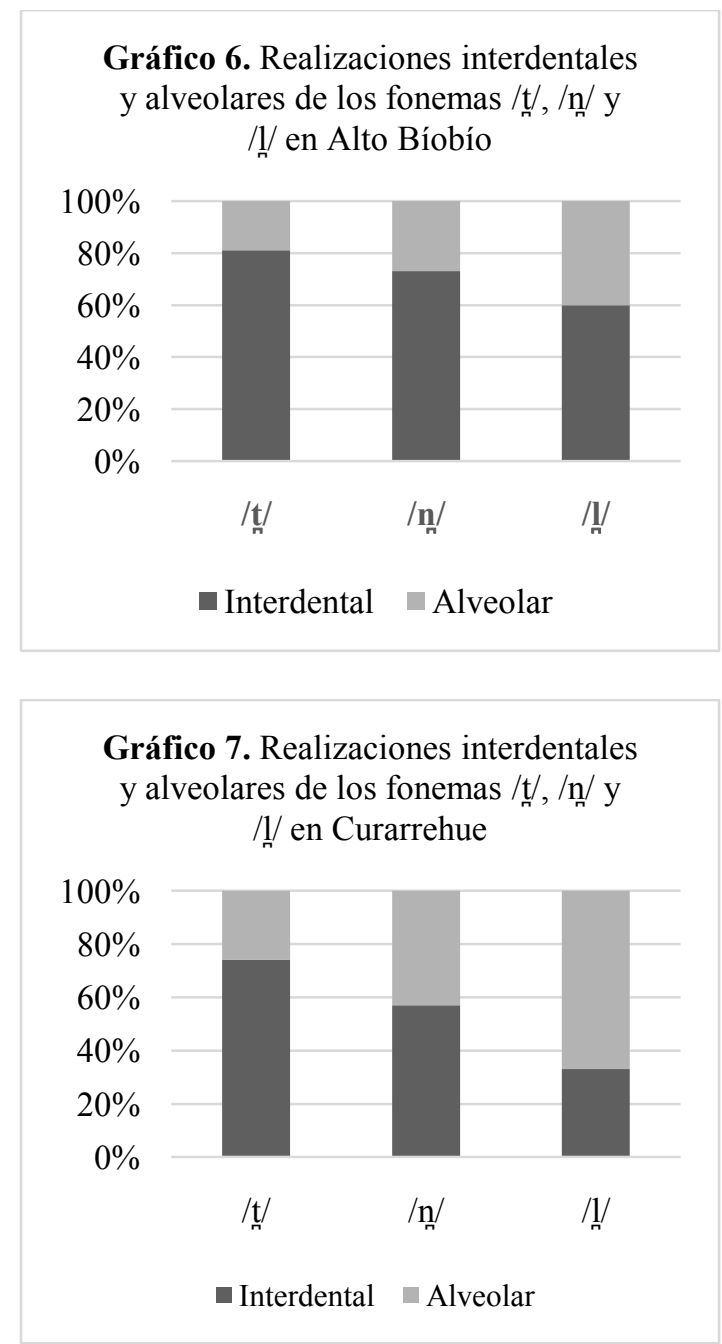

Nótese también las tendencias similares, aunque para cada uno de los fonemas los porcentajes son más altos en Alto Biobío. Este fenómeno es particularmente visible en el caso del fonema /1/, el que, en Curarrehue, presenta, incluso, más realizaciones alveolares.

\section{CONCLUSIONES}

A la luz de las evidencias presentadas, podemos responder afirmativamente a las dos preguntas de investigación planteadas para este estudio. En efecto, mediante evidencia visual y cuantitativa, se pudo establecer que los segmentos interdentales [t], [n] y [1] se encuentran vigentes en el chedungun hablado en Alto Biobío; mientras que por medio del 
análisis distribucional, la consistencia en la producción de estos segmentos en determinadas palabras y colaboradores, y la evidencia palatográfica, se pudo establecer que dichos segmentos poseen estatus fonémico separado de sus contrapartes alveolares $[\mathrm{t}]$, [n] y [1]. En este contexto, la notación que aplica es: /t/, /n/, / / /, /t/, /n/ y /1/. Es admisible añadir que lo afirmado es especialmente visible en la generación del rango etario más alto (adultos y ancianos) y de las comunidades más extremas (Trapa Trapa/Butalelbun, por el valle del Queuco; y Guallali/El Barco, por el valle del Biobío).

Al comparar los resultados que se presentan en Alto Biobío con los que se presentan en Sánchez y Salamanca (2015), y en Pérez (2014), para otras dos variedades cordilleranas (mapudungun hablado en Lonquimay y Curarrehue, respectivamente), se puede observar que estos no presentan mayores asimetrías, aunque es posible observar una tendencia a un mayor mantenimiento de estos segmentos en Alto Biobío y Lonquimay, que en Curarrehue.

Dicho esto, es importante señalar que si bien las evidencias expuestas respaldan la hipótesis de la vigencia de las consonantes interdentales [t], [n] y [1], en tanto fonos y en tanto fonemas, hay casos en los que se advierte una tendencia a la desfonologización de estos segmentos, ello se manifiesta en dos procesos: a) una tendencia a realizar con segmentos alveolares aquellas palabras que en la literatura y en los hablantes más competentes del sector han sido registradas con segmentos interdentales (lo que podríamos etiquetar como un proceso de hiperalveolarización) y b) una tendencia a realizar con segmentos interdentales aquellas palabras que en la literatura y en los hablantes más competentes del sector han sido reportadas con realizaciones alveolares (lo que podríamos denominar como un proceso de hiperdentalización). Por cierto, el primero de ellos es más frecuente y afecta en mayor grado a los colaboradores que se ubican en el rango etario más joven y de las comunidades más expuestas al contacto, por lo que debe ser un foco a relevar en futuras investigaciones. En cualquier caso, hemos de enfatizar que, en el cómputo general, estos casos constituyen una excepción, pues la norma observada es la oposición consistente entre los segmentos alveolares [t], $[\mathrm{n}]$ y [1] y los interdentales [t], [n] y [1], y, en ese contexto, con los datos de que disponemos, no podemos respaldar la hipótesis de la pérdida de las interdentales, o, dicho de otra manera, nuestros datos respaldan la hipótesis del mantenimiento, vigencia y vitalidad de los segmentos interdentales en habla adulta, tanto en su estatus de fonos como de fonemas, opuestos a los fonemas alveolares correspondientes, esto es: $/ \mathrm{t} /, \mathrm{m} / \mathrm{y} / \mathrm{I} /$ opuestos a $/ \mathrm{t} /, \mathrm{n} /, / 1 /$, respectivamente.

Universidad de Concepción*

Departamento de Español

Facultad de Humanidades y Arte

Casilla 160-C Correo 3, Concepción (/Chile)

gaston.salamanca@gmail.com 
Reanálisis de aspectos controversiales de la fonología del chedungun hablado

Universidad de Concepción**

Departamento de Español

Facultad de Humanidades y Arte

Casilla 160-C, Correo 3, Concepción (Chile)

jaimesotob@gmail.com

Universidad de La Frontera***

Departamento de Lenguas, Literatura y Comunicación

juan.painequeo@ufrontera.cl

Universidad de Concepción***

Programa de Magister Lingüistica Aplicada

Facultad de Humanidades y Arte

Casilla 160-C, Correo 3, Concepción (Chile)

mjimenezm@udec.cl

Este artículo responde una de las preguntas de investigación centrales del proyecto FONDECYT 1131095.

\section{OBRAS CITADAS}

Álvarez-Santullano, Pilar. (1986a). Descripción Fonológica del huilliche, un dialecto del mapuche o araucano del centro-sur de Chile. Tesis de Magíster en Artes con Mención en Lingüística. Universidad de Concepción, Concepción.

Álvarez-Santullano, Pilar. (1986b). "Descripción fonemática del Huilliche: estudio comparativo". Alpha, 45-50.

Anderson, Victoria. (2008). "Static Palatography for Language Fieldwork". Language Documentation \& Conservation, 1-27.

De Augusta, fray Félix José. (1916). Diccionario araucano-español y españolaraucano. Santiago de Chile: Imprenta Universitaria.

Burquest, Donald. Phonological Analysis: A functional approach. Dallas: SIL International, 2009. Existe una versión electrónica disponible en:

http://www.sil.org/silepubs/Pubs/52264/Burquest_AnalisisFonologico_52264.pdf.

Catrileo, María. (1995). Diccionario Lingüistico-etnográfico. Santiago: Andrés Bello.

Croese, Robert. (1980). "Estudio dialectológico del mapuche". Estudios Filológicos, 7-38.

Echeverría, Max. (1964). "Descripción fonológica del mapuche actual". Boletín del Instituto de Filología de la Universidad de Chile, 13-59.

Henríquez, Marisol. (2004). "Interferencias del sistema fonológico español en el sistema fonológico mapuche de jóvenes hablantes bilingües". $R L A, 93-106$.

International Phonetic Association. (2005). "The International Phonetic Alphabet". Recuperado en mayo de 2013 de https://www.langsci.ucl.ac.uk/ipa/IPA chart_(C)2005.pdf 
Lagos, Daniel. (1981) "El estrato fónico del mapudungu(n)". Nueva Revista del Pacífico, 42-66.

Lagos, Daniel. (1984). "Fonología del mapuche hablado en Victoria". Actas Jornadas de Lengua y Literatura Mapuche, 41-50.

Painequeo, Héctor. (2015). El estatus fonológico de los segmentos (inter)dentales [t], [I], [n], y el fono alveopalatal fricativo [J] en el sistema fonológico de la lengua mapuche del sector Budi, de la región de La Araucanía, Chile. Tesis para optar al grado de Doctor en Lingüística. Universidad de Concepción, Concepción.

Pérez, Chery. (2014). Fonemas segmentales y alófonos del mapuzungun hablado en Curarrehue y determinación de los grafemas más idóneos para su representación. Tesis para optar al grado de Magíster en Lingüística. Universidad de Concepción, Concepción.

Pike, Kenneth. (1947). Phonemics. A technique for Reducing Languages to writing. The University of Michigan Press: Ann Arbor.

Sadowsky, Scott. (2013). Héctor Painequeo, Gastón Salamanca y Heriberto Avelino. "Mapudungun". Journal of the International Phonetic Association, 87-96.

Salamanca, Gastón. (1997). "Fonemas segmentales del pehuenche hablado en el Alto Biobío". RLA, 113-124.

Salamanca, Gastón, Elizabeth Aguilar, Karen Alvear y Catherinne Barrientos. (2009). "Mapuche hablado en Melipeuco: Fonemas segmentales, fonotaxis y comparación con otras variedades". Logos, 74-95.

Salamanca, Gastón y Elizabeth Quintrileo. (2009). "Fonemas segmentales y muestra lexical del mapudungu hablado en Tirúa". RLA, 13-35.

Salamanca, Gastón, Edgardo Cifuentes y Mauricio Figueroa. (2011). "Sistematización de criterios para la determinación de fonos, fonemas y formas básicas de los fonemas: una herramienta para la investigación y la docencia". Boletín de Filología, 107-133.

Salamanca, Gastón; Daniela Mena y Marisol Henríquez. (2015). "Frecuencia y distribución de vocales ensordecidas en el habla de escolares pehuenches de 2 comunidades de Alto Biobío (Butallebun y Cauñicu)". Nueva Revista del Pacífico 62, 76-109.

Salas, Adalberto. (1997). "Pares mínimos y estatus fonémico: ¿causa o consecuencia?". RLA, 125-134.

_ (1992). El mapuche o araucano de Chile. Fonología, gramática y antología de cuentos. Madrid: Fundación MAPFRE América.

— (1978). "Mapuche-español. Análisis fonológico contrastivo". VICUS, Cuadernos-Lingüistica, : 57-86.

_ (1976). "Esbozo fonológico del mapudungu, lengua de los mapuches o araucanos de Chile central". Estudios Filológicos, 143-153.

Sánchez, Gilberto. (1989). "Relatos orales en pewenche chileno". Anales de la Universidad de Chile. Estudios en honor de Yolando Pino Saavedra, 289-360. 
Reanálisis de aspectos controversiales de la fonología del chedungun hablado

Sánchez, Makarena y Gastón Salamanca. (2015). "El mapuche hablado en Lonquimay: Fonemas segmentales, fonotaxis y comparación con otras variedades. Literatura y Lingüistica, 295-332.

Smeets, Ineke. A Mapuche Grammar. (1989). Doctoral Dissertation. Rijksuniversiteit te Leiden, Leiden.

Valdivia, Luis de. Arte y gramática general de la Lengua que corre en todo el Reyno de Chile, en Lima por Francisco del Canto, año 1606, edición facsimilar de Julio Platzmann, Leipzig, B. G., 1606. 